\title{
Análise e otimização da transmissão de dados em Linhas Digitais do Assinante
}

\author{
Diogo L. Silva, Glória J. A. Oliveira, Johelden C. Bezerra e Raimundo A. S. Costa.
}

\begin{abstract}
Resumo- A Linha Digital do Assinante (DSL) é uma tecnologia de transmissão de dados em banda larga que aproveita as redes telefônicas existentes. A linha telefônica possui varias limitações, sendo a principal o crosstalk, o qual limita a taxa de transmissão de dados do DSL. Novas técnicas de alocação de potência estão sendo desenvolvidas, as quais são conhecidas como Gerenciamento Dinâmico do Espectro (DSM - Dynamic Spectrum Management). Testes em uma linha real foram realizados e os resultados foram comparados com valores padronizados através de simulações. Por fim, o uso de técnicas de DSM foram testadas através de simulações para o ambiente real.
\end{abstract}

Palavras-Chave-ADSL, Crosstalk, DSM, ASB.

Abstract- The Digital Subscriber Line (DSL) is a technology for broadband data transmission which uses the existent telephonic networks. The telephone lines has several limitation, and the main is the crosstalk, which limit the maximum data rates transmission on DSL. News techniques of power allocation have been developed, which are knows with DSM - Dynamic Spectrum Management. Test in real lines were realized and the results were compare with pattern thought simulation. Finally, the DSM techniques were tested thought simulation for real environment.

Keywords - ADSL, Crosstalk, DSM, ASB.

\section{INTRODUÇÃO}

A Linha Digital do Assinante (Digital Subscriber Line - DSL) é uma tecnologia de transmissão digital de dados em banda larga que utiliza a rede telefônica existente. Todavia, a comunicação de dados através da linha telefônica sofre diversas degradações, sendo a principal o crosstalk, fenômeno que ocorre devido ao agrupamento dos pares metálicos que constituem um mesmo binder (grupo de par-trançados em um cabo telefônico) provocando o surgimento do acoplamento eletromagnético entre eles.

Este trabalho objetiva realizar a análise e otimização da transmissão de dados em sistemas DSL, especificamente do ADSL (Assímetric Digital Subscriber Line), através de medições realizadas em campo com cenários reais e de simulações usando as mesmas topologias desses cenários com técnicas de Gerenciamento Dinâmico do Espectro - DSM (Dynamic Spectrum Management), as quais objetivam melhorar as taxas de transmissão de dados através das linhas telefônicas.

$\mathrm{Na}$ seção II, será apresentado o modelo de sistema DSL, descrevendo o canal e as limitações impostas pelo meio de transmissão. Na seção III será mostrado o Gerenciamento Dinâmico do Sistema para a otimização dos cenários.

Diogo Silva, Glória Oliveira e Raimundo Costa, Instituto de Estudos Superiores da Amazônia - IESAM, Johelden Bezerra, Universidade Federal do Pará, Centro Federal de Educação Tecnológica do Pará (CEFET) e IESAM. Belém, Brasil, E-mails: idiogolima@gmail.com, gjulianaoliveira@gmail.com, adriano.zeiny@gmail.com, johelden@yahoo.com.br.
Na seção IV serão apresentados os cenários avaliados e os resultados das simulações. $\mathrm{E}$ por fïm, na seção $\mathrm{V}$ conclui-se o trabalho através das análises dos resultados obtidos.

\section{Modelo do SiSTEMA DSL}

A transmissão de dados no DSL é feita pela sincronização de dois modems, através de uma rede de pares metálicos compartilhada por outros usuários que também podem estar usando DSL. Assim, quando existe mais de um usuário compartilhando um mesmo binder, e que estejam com seus modems ligados ao mesmo tempo, ocorrerá acoplamento eletromagnético entre os partrançados, fenômeno conhecido como crosstalk.

O crosstalk pode ser classificado em dois tipos: NEXT (Near End Crosstalk) ou FEXT (Far End Crosstalk). O NEXT refere-se ao sinal interferente gerado por um transmissor que está localizado do mesmo lado do receptor afetado, vide Figura 1. Mas, seu efeito é evitado devido a FDD (Frequency Division Duplex) ou a TDD (Time Division Duplex), ou seja, isto é possível devido à existência de bandas de freqüências distintas para transmissão em downstream e upstream. Já o FEXT, o principal tipo de crosstalk, refere-se ao sinal originado de um transmissor localizado no lado oposto ao do receptor afetado, conforme apresentado na Figura 1. A Figura 1, também apresenta além do NEXT e FEXT, outras fontes geradoras de ruído, tais como: ruído impulsivo (proveniente de outros serviços de telecomunicações) e radiofreqüências externas. Por fïm, o comprimento do cabo também limita a taxa de transmissão devido à atenuação que é função da distância. [4]

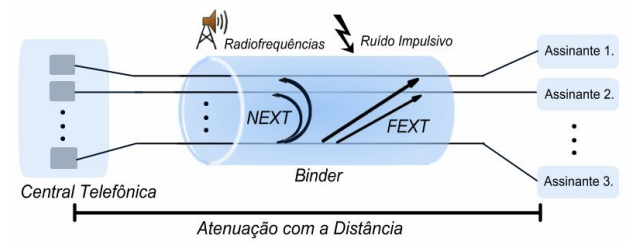

Fig. 1. Representação dos efeitos que degradam a transmissão de dados pela linha telefônica.

\section{GERENCIAMENTO DinÂMICO DO SiSTEMA}

As tecnologias DSL atuais se utilizam do gerenciamento estático de espectro (SSM - Static Spectrum Management), a qual define que todos os usuários utilizam o canal como se o mesmo estivesse na pior condição de ruído, e todos os usuários transmitem com os mesmos níveis de densidades espectrais de potência (PSD - Power Spectral Density). O SSM, da forma como trabalha, desperdiça o meio de transmissão.

Para otimizar a transmissão do sistema DSL usa-se técnicas adaptativas de alocação de potência conhecidas como DSM. Este se baseia nos ajustes dinâmicos das PSD's nas transmissões multiusuários, os quais dependem das características do canal e do nível de crosstalk em cada linha [3]. Na Figura 2 são ilustradas as PSD's usando SSM (estática) e DSM (dinâmica) respectivamente. 


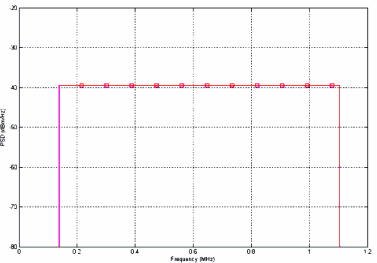

(a)

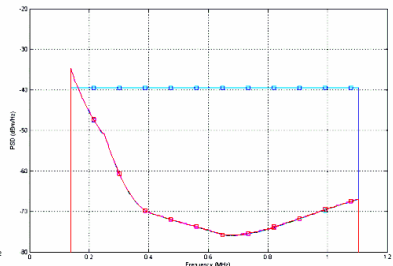

(b)
Fig. 2. PSD $(\mathrm{dBm} / \mathrm{Hz})$ para (a) SSM e (b) DSM

Para este artigo, considerou-se o problema que o DSM lidará é o de taxa adaptativa (pois é o mais discutido na literatura) e que os modems usam DMT (discrete multi-tone). O problema é formulado por $[3,4]$ :

$$
\underset{\mathbf{p}_{1}, \ldots, \mathbf{p}_{\mathbf{N}}}{\max } R_{1} \text { dado que } R_{n} \geq R_{n}^{\text {alvo }} \forall n>1,
$$

onde $\mathbf{p}_{\mathrm{n}}$ é o vetor formado pelas PSD's em cada tom para o usuário $n$, i.e., $\mathbf{p}_{\mathbf{n}}=\left[p_{n}^{1}, \ldots, p_{n}^{K}\right]$, onde k é o tom de cada subcanal.

A Equação (1) considera um sistema com $N$ usuários, onde deseja-se maximizar da taxa do usuário 1 dado que as taxas de todos os outros $N-1$ usuários sejam maiores ou iguais a uma taxaalvo.

É fundamental também a restrição de potência dos modems. O somatório dos elementos do vetor $\mathbf{p}_{\mathrm{n}}$ não pode exceder a potência máxima disponível ao modem. Dessa forma,

$$
\sum_{k=1}^{K} p_{n}^{k} \leq P_{n}^{\max } \quad \forall n
$$

onde $P_{n}^{\max }$ é a potência máxima disponível para o modem $n$.

Existem na literatura algumas técnicas para resolver o problema apresentado na Equação (1), neste trabalho usou-se o algoritmo ASB proposto por Cendrillon em 2006 [1], o qual baseia-se no conceito de linha virtual, onde cada usuário tenta maximizar a taxa de dados dessa linha, escolhida sempre como a pior do cenário, sujeito a uma taxa alvo e a restrição de potência. Assim, a Equação (1) pode ser reescrita como:

$$
\begin{aligned}
\max _{p_{n}} R^{n, r e f} \text { tal que, } R^{n} & \leq R^{n, t \arg e t}, \\
& \text { tal que, } \sum_{k \in K} p_{n}^{k} \leq P^{n, t \arg e t} .
\end{aligned}
$$

Detalhes do algoritmo ASB que resolve o problema da Equação (3) podem ser encontrados em [1].

\section{IV - CENÁRIOS E RESUlTAdOS}

Nesta seção serão apresentados os resultados das simulações com o algoritmo ASB e das medições realizadas em campo com o analisador de linha WISE [2].

O cenário analisado, apresentado na Figura 3, possui 31 usuários de ADSL no mesmo Binder, usando pares metálicos AWG 26 (bitola de $0,4 \mathrm{~mm}$ ), e todos localizados a uma mesma distância de aproximadamente 1,62 km da Central Telefônica, haja vista que todos se encontram em um mesmo prédio com o armário telefônico interno. A Tabela I apresenta os resultados das medições.

\section{TABELA I}

Dados coletados com o equipamento WISE

\begin{tabular}{|r|r|r|r|}
\hline & Dados coletados com o equipamento WISE. \\
\hline & Atenuação(dB) & SNR & Taxa (Mbps) \\
\hline Downstream & 30,6 & 31,5 & 6,27 \\
\hline Upstream & 17 & 31 & 0,8 \\
\hline
\end{tabular}

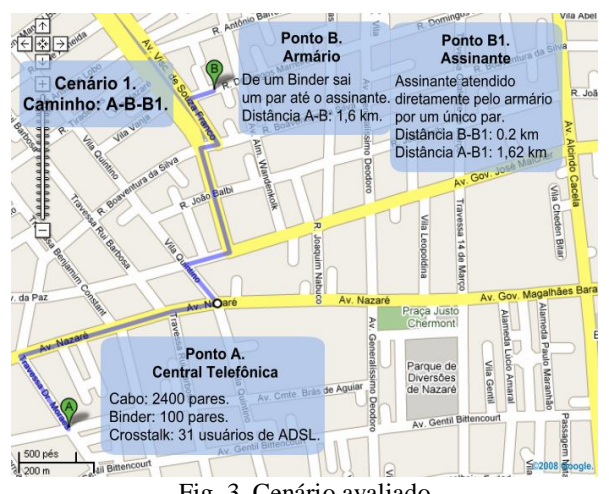

Fig. 3. Cenário avaliado

Utilizando um software de DSM desenvolvido no MatLab, foi realizado simulações com o cenário em análise e pode-se verificar que os resultados das simulações (6,02 Mbps para cada usuário) estão de acordo com os valores obtidos pelas medições em campo. Sendo assim, é possível através de simulações preverem as taxas de dados que os assinantes DSL podem atingir. Após isso, com a ajuda do algoritmo ASB, maximizou-se a taxa de transmissão de dados para uma das linhas e obteve-se $11,95 \mathrm{Mbps}$, enquanto que as demais foram mantidas em uma taxa alvo de 2 Mbps. Assim, com o algoritmo ASB consegue-se, praticamente, duplicar a taxa de downstream para usuário de interesse e garantir que os outros usuários fiquem com determinada taxa alvo. A Figura 4 descreve os resultados obtidos.

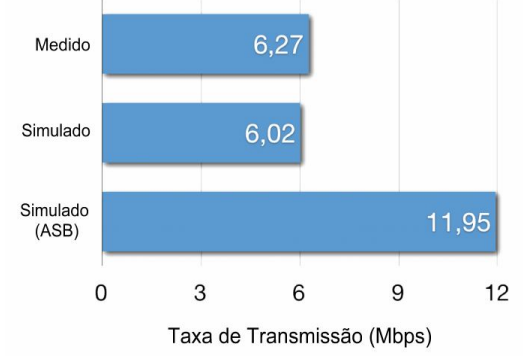

Fig. 4. Resultados obtidos

\section{CONCLUSÕES}

Os resultados obtidos demonstram a eficiência do equipamento WISE e do software em MatLab para DSL, o qual foi implementado de acordo com os padrões DSL. A eficiência do algoritmo de gerenciamento dinâmico de espectro ASB foi testada e através dos resultados prevê-se que o sistema DSL, com ajuda dos algoritmos DSM, terá seu uso prolongado por fornecer alta taxa de transmissão de dados aos assinantes.

\section{AGRADECIMENTOS}

A Deus pela sua imensa paciência, a Oi e ao nosso orientador Johelden Bezerra pela confiança e incentivo a pesquisa.

\section{REFERÊNCIAS}

[1] J. Huang, R. Cendrillon, M. Chiang, M. Moonen, "Autonomous Spectrum Balancing (ASB) for Frequency Selective Interference Channels", IEEE International Symposium Information Theory (ISIT), Seattle, July 2006.

[2] Datasheet do equipamento WISE TSW400DSL2+ acessado em 07/01/2008, disponível em: http://www.wi.com.br/pdf/folder_tsw400dsl2 +_en_US_v2.pdf.

[3] D. L. Silva, G. J. Oliveira e R. A. Costa, "Análise e Otimização de Linhas Digitais do Assinante", TIC, Simpósio Internacional de Iniciação Cientifica da USP, Novembro 2007.

[4] J. C. Bezerra, "Método para Otimização da Taxa de Transmissão em Linhas Digitais do Assinante usando Gerenciamento Dinâmico do Espectro”. Qualificação de Doutorado, Universidade Federal do Pará, 2007. 